Pacific Northwest

National Laboratory

Operated by Battelle for the

U.S. Department of Energy

\title{
Nondestructive Characterization of Aged Components
}

\author{
PD Panetta \\ FA Garner \\ MB Toloczko \\ II Balachov
}

October 2003

Prepared for the U.S. Department of Energy

under Contract DE-AC06-76RL01830 


\title{
DISCLAIMER
}

This report was prepared as an account of work sponsored by an agency of the United States Government. Neither the United States Government nor any agency thereof, nor Battelle Memorial Institute, nor any of their employees, makes any warranty, express or implied, or assumes any legal liability or responsibility for the accuracy, completeness, or usefulness of any information, apparatus, product, or process disclosed, or represents that its use would not infringe privately owned rights. Reference herein to any specific commercial product, process, or service by trade name, trademark, manufacturer, or otherwise does not necessarily constitute or imply its endorsement, recommendation, or favoring by the United States Government or any agency thereof, or Battelle Memorial Institute. The views and opinions of authors expressed herein do not necessarily state or reflect those of the United States Government or any agency thereof.

\author{
PACIFIC NORTHWEST NATIONAL LABORATORY \\ operated by \\ BATTELLE \\ for the \\ UNITED STATES DEPARTMENT OF ENERGY
}

under Contract DE-AC06-76RL01830

Printed in the United States of America

Available to DOE and DOE contractors from the

Office of Scientific and Technical Information,

P.O. Box 62, Oak Ridge, TN 37831-0062;

ph: (865) 576-8401

fax: (865) 576-5728

email: reports@adonis.osti.gov

\begin{abstract}
Available to the public from the National Technical Information Service, U.S. Department of Commerce, 5285 Port Royal Rd., Springfield, VA 22161 ph: (800) 553-6847 fax: (703) 605-6900

email: orders@ntis.fedworld.gov

online ordering: http://www.ntis.gov/ordering.htm
\end{abstract}

This document was printed on recycled paper.

$(8 / 00)$ 


\title{
Nondestructive Characterization of Aged Components
}

\author{
Prepared by Paul D. Panetta ${ }^{1}$, Mychailo B. Toloczko ${ }^{1}$, Frank A. Garner ${ }^{1}$, and Iouri I. \\ Balachov $^{2}$ \\ ${ }^{1}$ Pacific Northwest National Laboratory \\ P.O. Box 999 \\ Richland, Washington 99352 \\ ${ }^{2}$ SRI International \\ Menlo Park, CA
}

\section{Introduction}

It is known that high energy radiation can have numerous effects on materials. In metals and alloys, the effects include, but may not be limited to, mechanical property changes, physical property changes, compositional changes, phase changes, and dimensional changes. Metals and alloys which undergo high energy self-irradiation are also susceptible to these changes. One of the greatest concerns with irradiation of materials is the phenomenon of void swelling which has been observed in a wide variety of metals and alloys. Irradiation causes the formation of a high concentration point defects and microclusters of vacancies and interstitials. With the assistance of an inert atom such as helium, the vacancy-type defects can coalesce to form a stable bubble. This bubble will continue to grow through the net absorption of more vacancy-type defects and helium atoms, and upon reaching a certain critical size, the bubble will begin to grow at an accelerated rate without the assistance of inert atom absorption. The bubble is then said to be an unstably growing void. Depending on the alloy system and environment, swelling values can reach in excess of $50 \% \Delta \mathrm{V} / \mathrm{V}_{\mathrm{o}}$ where $\mathrm{V}_{\mathrm{o}}$ is the initial volume of the material. Along with dimensional changes resulting from the formation of bubbles and voids comes changes in the macroscopically observed speed of sound, moduli, electrical resistivity, yield strength, and other properties. These effects can be detrimental to the designed operation of the aged components.

In situations where irradiation has sufficient time to cause degradation to materials used in critical applications such as nuclear reactor core structural materials, it is advisable to regularly survey the material properties. It is common practice to use surveillance specimens, but this is not always possible. When surveillance materials are not available, other means for surveying the material properties must be utilized. Sometimes it is possible to core out a small sample which may be used for material properties measurements. A more appealing solution is to use nondestructive evaluation (NDE) methods. 
A variety of NDE methods exist with some techniques being specific to the measurement of a particular material property. As far back as the early 1970's, NDE has been under investigation as a potential means to evaluate the properties of irradiated materials. Where void swelling, mechanical property, and microstructural changes have been a concern, ultrasonic techniques are excellent NDE candidates for providing information about these properties for inservice structures. Selected electromagnetic techniques have also shown promise. Researchers at PNNL have expertise in both the basic understanding of materials degradation and the NDE methodologies to quantify the degradation to provide material properties such as speed of sound, density, and other material properties as will be described in the next section.

\section{Nondestructive measurement of material properties}

There are several nondestructive measurement techniques that are sensitive to material properties. We will summarize them below for the specific application of aged components. In addition, there are several measurements which are sensitive to other material properties which will be included for the reader's information. For the purpose of this white paper, the techniques will be presented with the following specific interests:

- $\quad$ Material properties from thin components

- $\quad$ Obtaining material properties from layered components

- Performing measurements without contacting the component

- Working with curved components

- Working in confined spaces

- Quantification of spatial variations in material properties

\section{$\underline{\text { Ultrasonic speed of sound }}$}

The most direct method for measuring the speed of sound in a material is to determine the time of flight for a sound wave that traverses a known distance. There are many types of waves that can be employed including longitudinal, shear, surface, and plate waves. Each type of field can be deployed in numerous configurations and can be used on layered components consisting of thin shells. Final implementation depends on striking a balance between resolution and ease of use. For dense materials, operating frequencies in the 1-20 MHz range can easily be utilized to determine the velocity of sound in shells having a thickness as low as 1-3 mm. These operating frequencies are easily obtained using off-the-shelf equipment. Figure 1 shows a schematic of a typical velocity measurement. Layered materials can be accommodated as an echo will be produced by the change in density of the material at the interface. A variety of techniques exist for introducing an ultrasonic wave into a material. An ultrasonic wave can be physically coupled into the material through various coupling agents including water and gels. Under certain circumstances the sound can be coupled through air for short distances. For conducting materials, Electromagnet Acoustic Transducers or EMATs can be utilized for generating sound waves. PNNL has expertise in measuring the speed of sound utilizing EMATs 
and can accurately measure speed of sound changes of less than $0.5 \%$. Curved surfaces can be accommodated using EMATs.

\section{Determination of Material Properties Utilizing Ultrasonic Techniques}

Once the speed of sound of various types of waves is determined, then other material properties can be determined. The ultrasonic velocity is a function of the

Moduli (Young's, Bulk, Shear)

Density/porosity

Texture (preferred grain orientation)

Stress

Strain

In practice, a measurement of the speed of sound provides information about all of these properties simultaneously. These competing mechanisms can convolute interpretation of speed of sound measurements, but fortunately, the effects of these property changes on the speed of sound are not all equal. For example, typical stress and strain levels achieved during plastic deformation of $20 \%$ produce changes to the speed of sound on the order of $1 \%$. Similar size changes occur for most common textures as well. For the case of degradation of aged components due to void formation, the velocity is affected much more strongly. For example, a $1 \%$ increase in the porosity due to swelling decreases the speed of sound by $\sim 1 \%$. Examples of measurements of the above properties will be provided below.

The velocity of sound is related to the elastic properties through the relation, $V_{I J} \rho \sqrt{C_{I J} / \rho}$, where and $C_{I J}$, are the density and the elastic constant, respectively. If the density is directly measured or assumed from engineering data tables, then one can determine the elastic constants of the material by measuring the speed of sound. While theories exist and accurately predict the wave propagation of many modes, a theory is not always available. In these cases, the speed of sound can be calibrated to changes in a material property using a set of known standards specimens.

\section{Quantification of void swelling}

When a material swells, both the macroscopic density (swelling) and the macroscopic elastic constants change. For in-service components, the best approach to measurement of swelling is to calibrate the speed of sound to swelling using a set of materials with similar properties to the in-service component. An example is shown in Figure 2 where the speed of sound as a function of porosity is plotted for powder metallurgical specimens with different degrees of porosity. Measurements on irradiated materials show the same trend with a decrease in velocity (and moduli) as porosity increases. Figure 3 shows the time of flight of sound waves 
in thin $(1 \mathrm{~mm})$ irradiated materials disks. The samples used for these measurements were cut from ducting that was irradiated in the EBR-II Fast Reactor.

By utilizing measurements of the longitudinal and shear wave velocities coupled with a knowledge of the density, the moduli for these materials have been determined and are plotted as a function of porosity in Figure 4. The points represent experimental measurements, and the lines are theoretical predictions based on changes to the velocity as a function of porosity. The velocities decrease $\sim 1 \%$ and the moduli decrease $\sim 2 \%$ for each $1 \%$ increase in porosity.

\section{$\underline{\text { Stress and strain measurements }}$}

The speed of sound is also affected by the degree of stress and strain in the materials. Evidence of this is shown in Figure 5, where the speed of sound for two shear waves of orthogonal polarization are plotted as a function of stress up to $10 \%$ plastic deformation. The changes seen in the elastic region are quite small, $\sim 0.5 \%$ at most. Once plastic deformation occurs, the changes are only $\sim 3 \%$. While these changes are small, they are easily measurable and can be used to quantify both the residual stress and the plastic strain. These types of measurements have been employed to determine the degree of plastic strain in thin-walled steel pipes. The birefringence, which is the ratio of the shear wave velocities, can be used to quantify the amount of plastic strain without knowing the thickness of the component. The birefringence is plotted versus plastic strain in Figure 6 for two different steel alloys.

\section{Grain Morphology}

In addition to the speed of sound, the density, the moduli, residual stress, and plastic strain, ultrasonic measurements can be utilized to determine other microstructural features, such as grain morphology (size and shape). These measurements rely on determining the amplitude of a traveling wave rather than the transit time. The amplitude of the traveling wave decreases as the ultrasound is scattered from grain boundaries due to orientation differences between each grain. The resulting is ultrasound returns to the sending transducer (backscattering), or energy is scattered in all directions creating a signal loss termed attenuation. A measurement of the ultrasonic backscattering, $\eta$, as a function of frequency and grain orientation is shown in Figure 7. The points are from experimental measurements, and the lines are from theoretical predictions of the backscattering for this duplex titanium alloy.

\section{Precipitates and Dislocations}

In addition to the materials properties which the speed of sound and the scattering can measure, dislocation properties can also be probed through measurements of the absorption or internal friction. One example of this interrelationship is shown in Figure 8, where the internal friction as a function of heat treatment is shown. These specimens have been heat treated to create nanometer-sized copper-rich precipitates to mimic degradation to welds in nuclear 
reactors pressure vessel walls. There is a distinct correlation with the macroscopic hardness for these heat treated materials.

\section{Field Deployment and Practical Applications}

The NDE group at PNNL has expertise in applying scientific rigor to solve practical problems. The group is well integrated with the electronics group and has customized electronics packages for specific applications. The group specializes in field deployable systems and finding engineering solutions based on sound scientific principals. Several of the field deployed devices have been commercialized and received R\&D 100 and/or FLC awards. PNNL has expertise with non-contact transduction utilizing EMATs, air coupling and dry coupling

\section{Summary and Conclusions}

There is a significant need to provide an in-service characterization tool to determine the speed of sound and density of aged components. A variety of methods exist for using ultrasonic sound waves to determine these properties. NDE methods in-use at PNNL are ideal for these applications. The speed of sound can be measured utilizing several different modalities as necessary to meet final configuration and materials needs. 


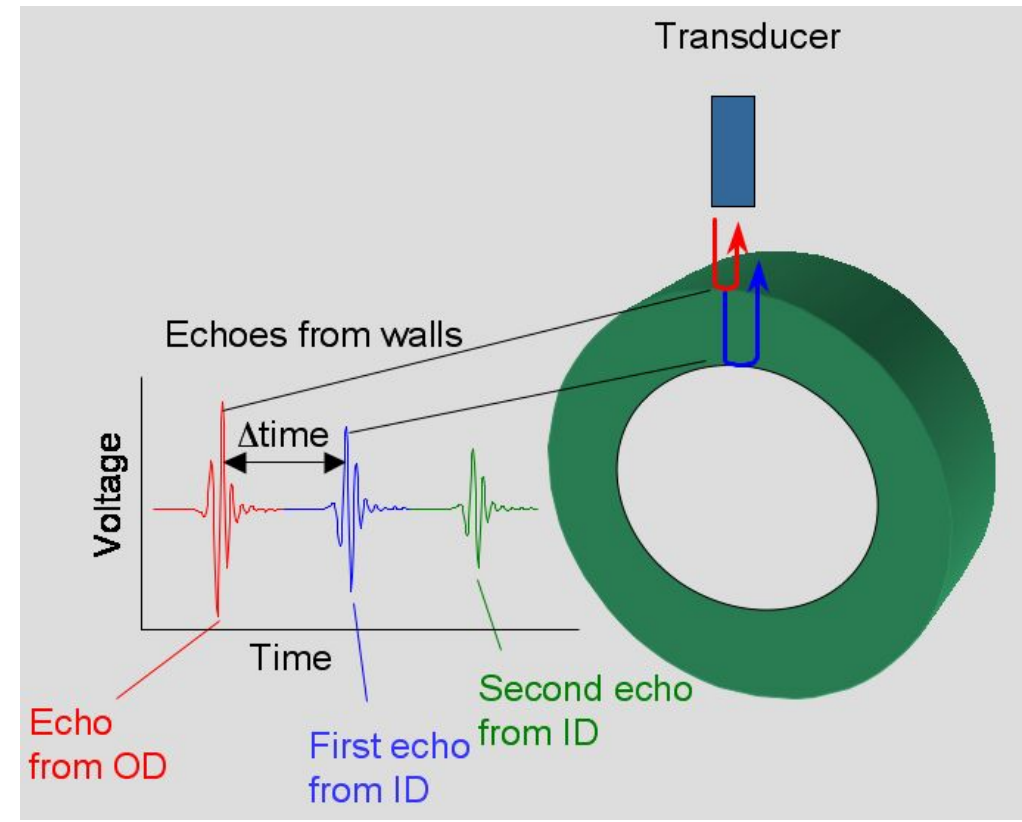

Figure 1 -- A typical measurement of the speed of sound. 


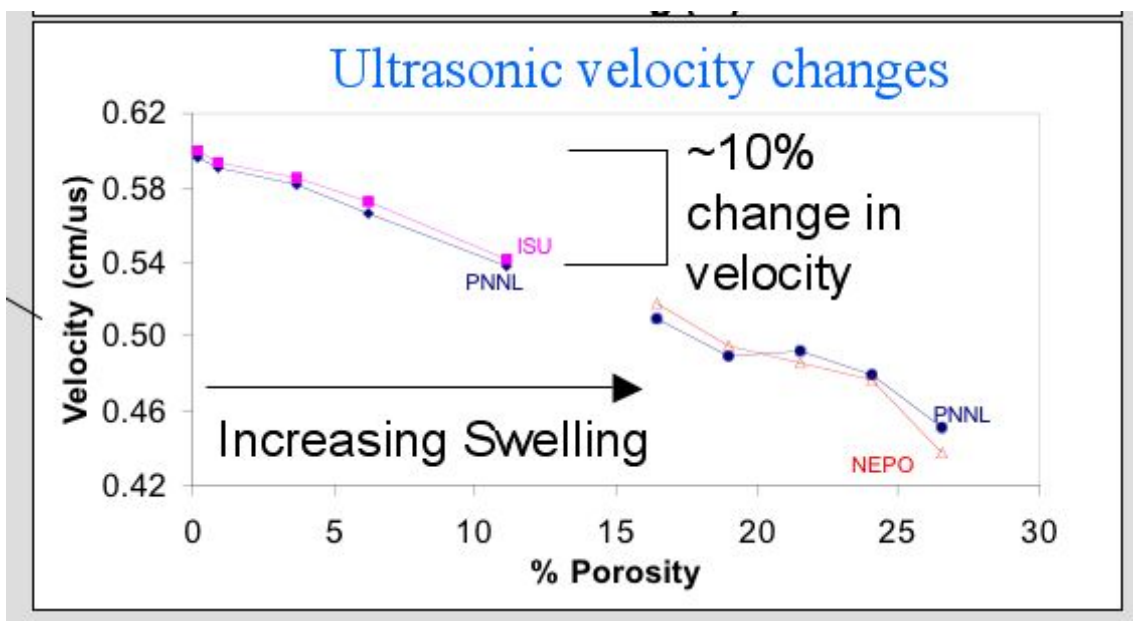

Figure 2 -- Variation in speed of sound with the porosity of powder-metallurgical samples. 


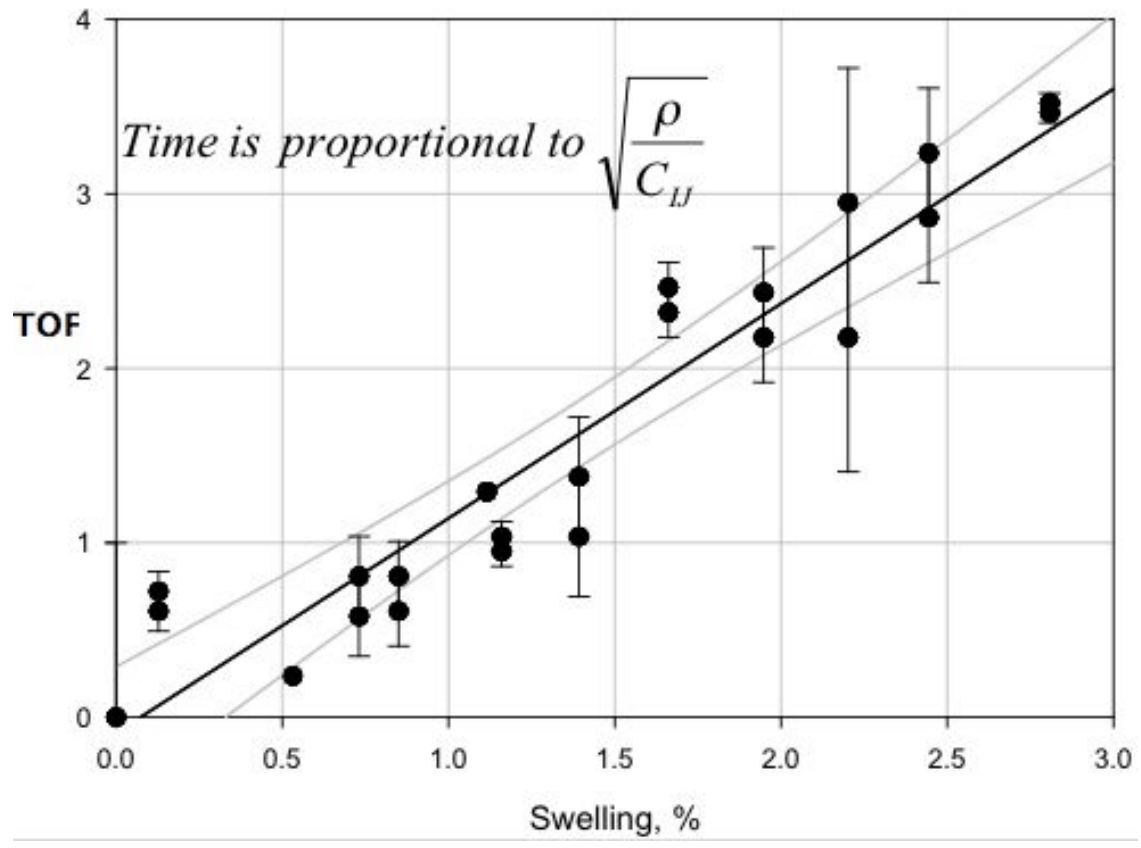

Figure 3 -- Variation in time of flight (TOF) as a function of swelling in 304 SS duct that was irradiated in the EBR-II Fast Reactor. 


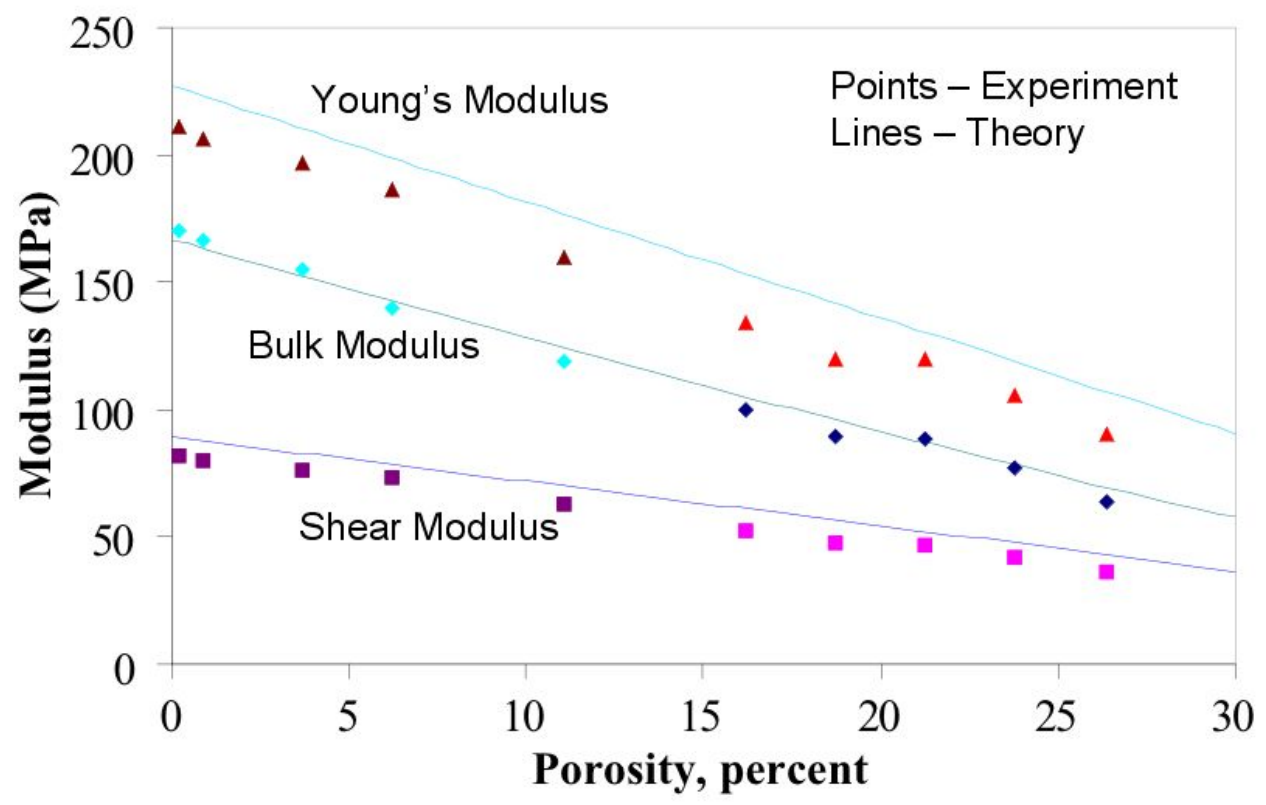

Figure 4 -- Variation in moduli as a function of the porosity in powder-metallurgical specimens. 


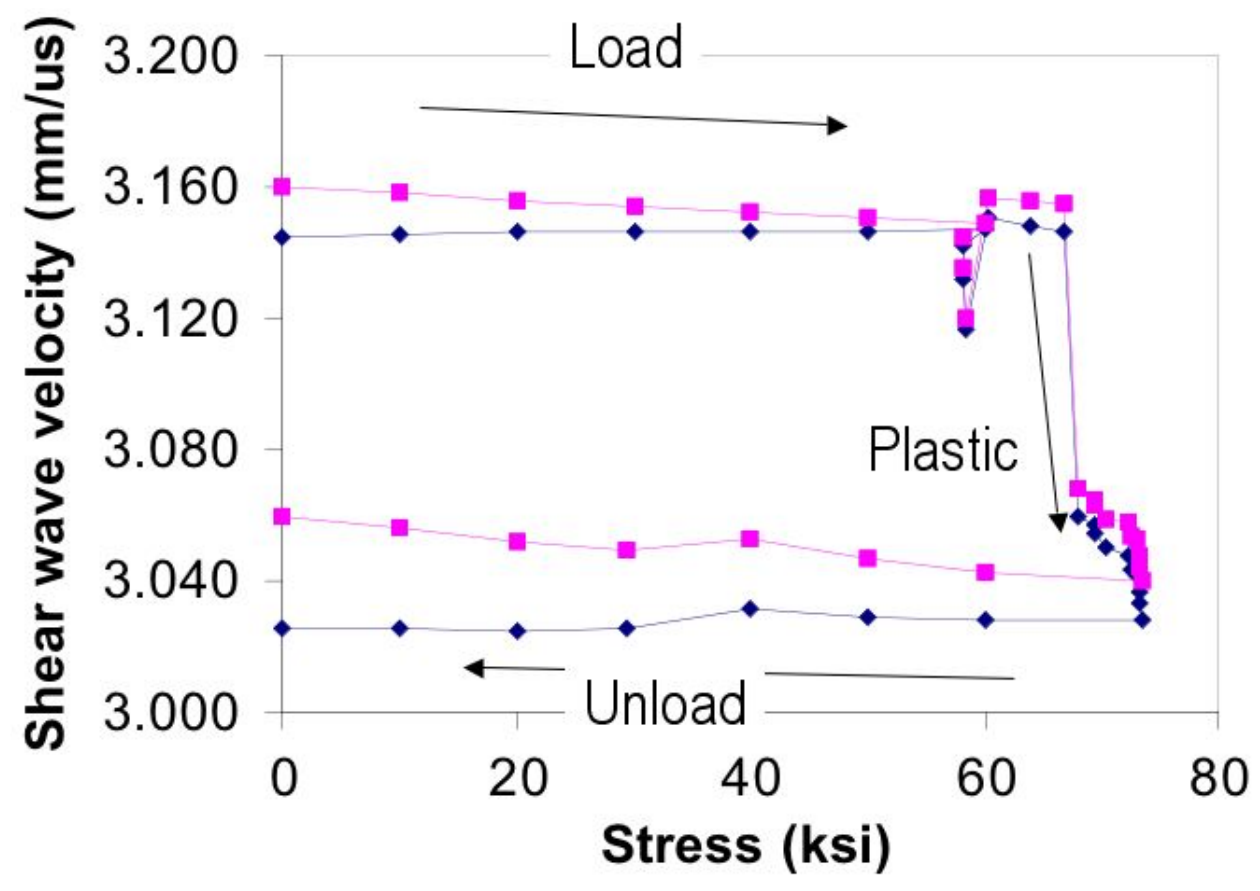

Figure 5 -- Speed of two shear waves of orthogonal polarizations as a function of stress in a lowalloy steel. 


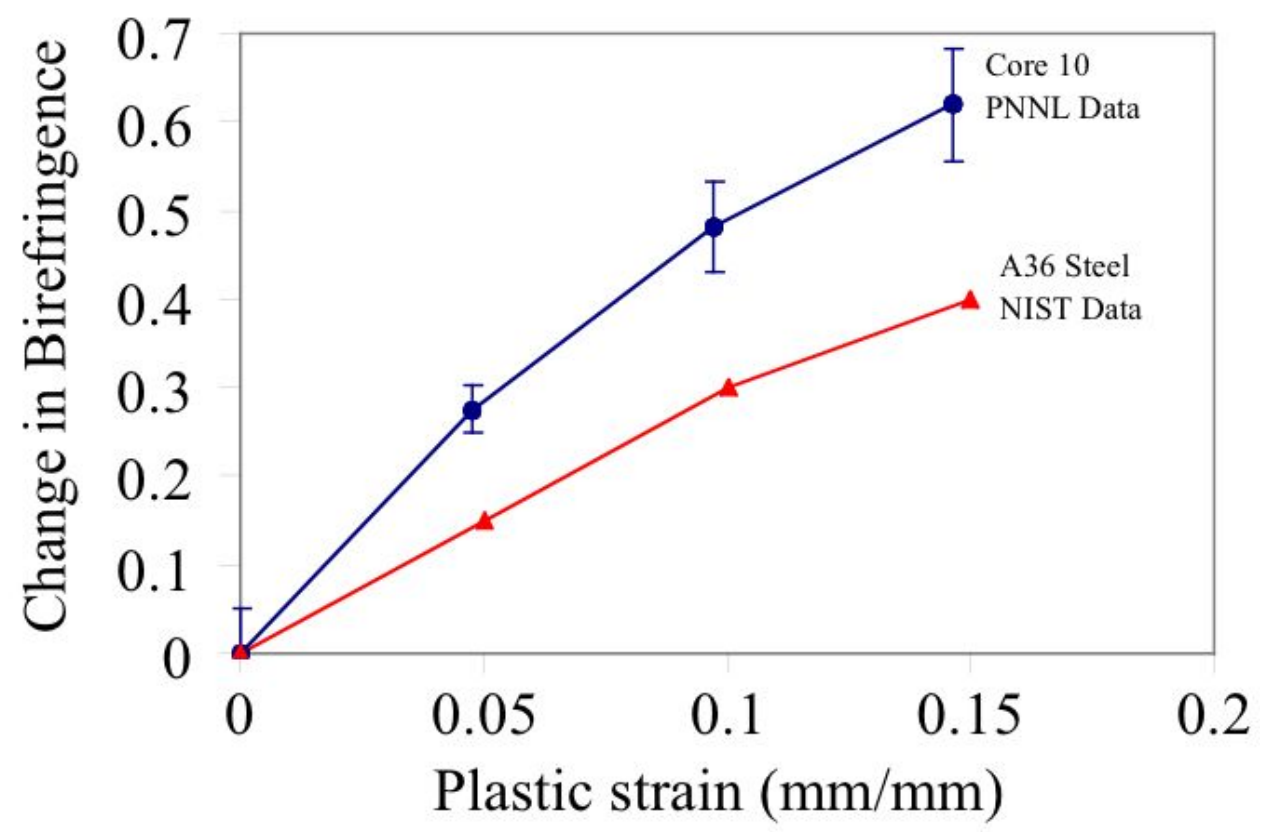

Figure 6 -- Birefringence plotted as a function plastic strain as measured from a set of test samples. 


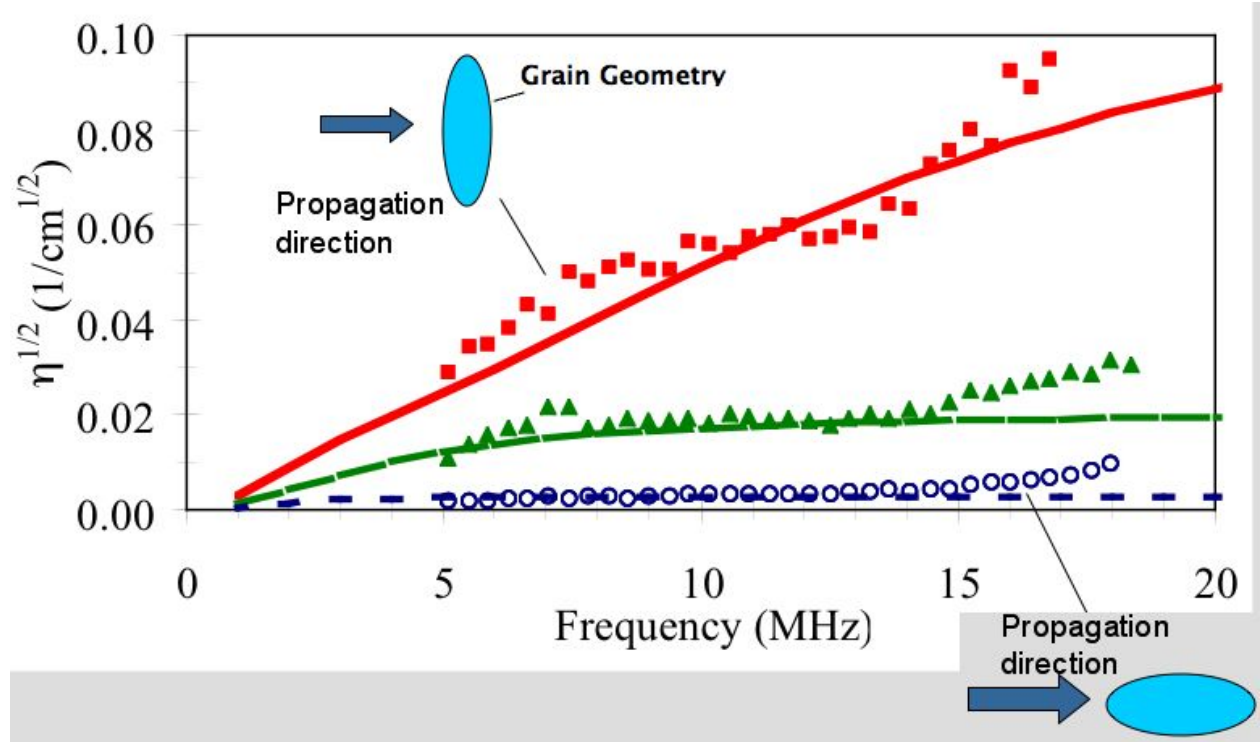

Figure 7 -- A measurement of backscattering, $\eta$, as a function of grain orientation relative to the propagation direction of a sound wave in a titanium alloy. 


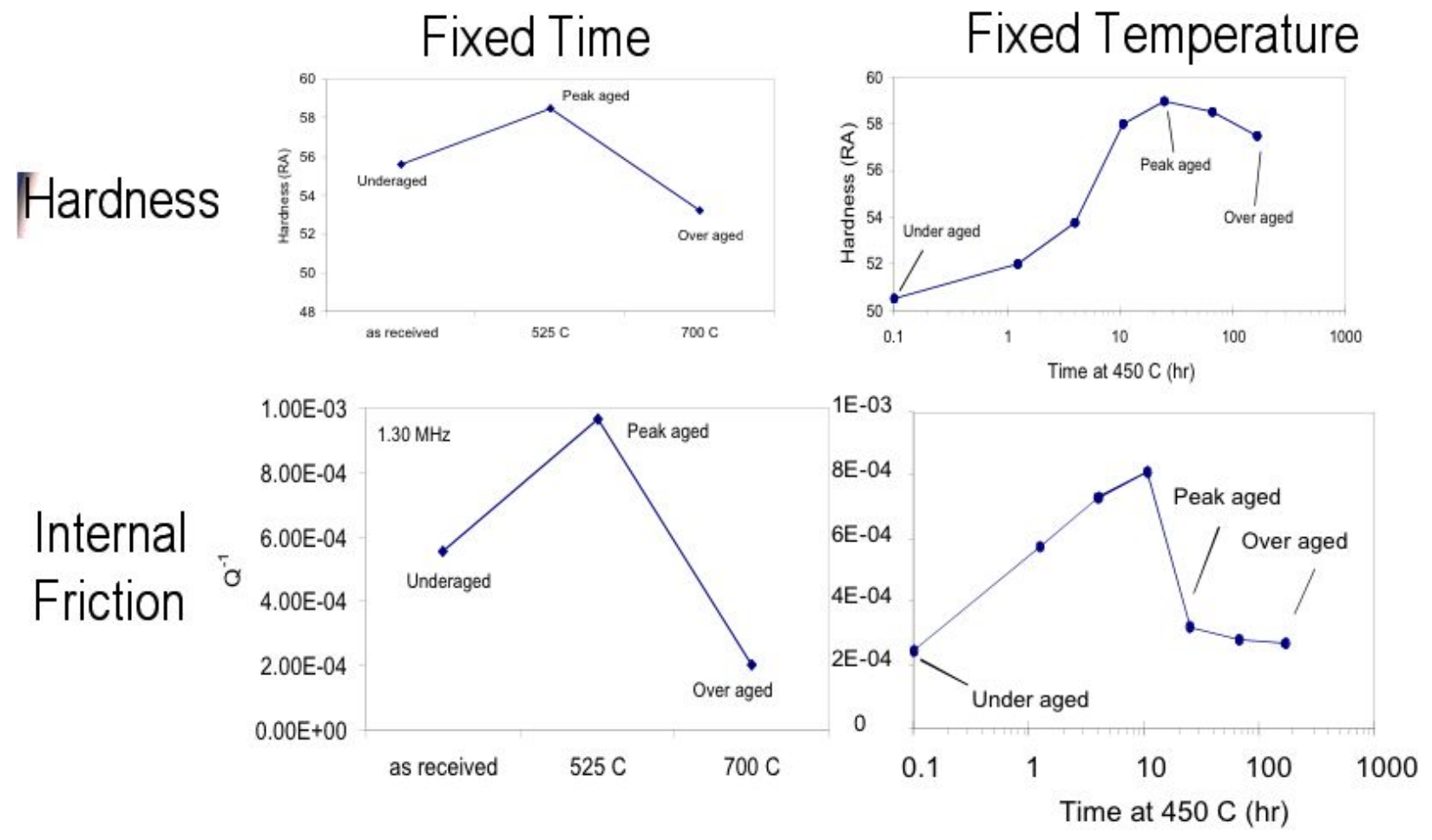

Figure 8 -- Internal friction measurements from ultrasonic waves compared to hardness measurements for a $\mathrm{Fe}-\mathrm{Cu}$ alloy. 